\title{
Venous Thromboembolism Due to Oral Contraceptive Intake and Spending Nights in a Vehicle -A Case from the 2016 Kumamoto Earthquakes-
}

\author{
Daisuke Sueta ${ }^{1}$, Rika Akahoshi ${ }^{1}$, Yoshinori Okamura ${ }^{2}$, Sunao Kojima ${ }^{1}$, Tomokazu Ikemoto ${ }^{1}$, \\ Eiichiro Yamamoto ${ }^{1}$, Yasuhiro Izumiya ${ }^{1}$, Kenichi Tsujita ${ }^{1}$, Koichi Kaikita ${ }^{1}$, \\ Hidetaka Katabuchi $^{2}$ and Seiji Hokimoto ${ }^{1}$
}

\begin{abstract}
A 40-year-old woman experiencing sudden dyspnea went to her personal doctor for advice. She was previously diagnosed with endometriosis and prescribed oral contraceptives for treatment. During earthquakes, she spent 7 nights sleeping in a vehicle. The patient had swelling and pain in her left leg and high D-dimer concentration levels. A contrast-enhanced computed tomography scan revealed a contrast deficit in the bilateral pulmonary artery and in the left lower extremity. She was diagnosed with pulmonary thromboembolism (PTE), and anticoagulation therapy was initiated. This present case is the first report of PTE attributed to the use of oral contraceptives after earthquakes.
\end{abstract}

Key words: thromboembolism, combined oral contraceptives, sleeping overnight in a vehicle

(Intern Med 56: 409-412, 2017)

(DOI: 10.2169/internalmedicine.56.7785)

\section{Introduction}

Long-fight thrombosis (LFT; traveler's thrombosis) is a term used to describe pulmonary thromboembolism (PTE) caused by long-term sedentary behavior; LFT was first reported by Simpson et al. in 1940 (1). In Japan, evacuees who slept in their cars at the time of a disaster suffered from PTEs due to a combination of dehydration (due to water and food shortages) and spending long periods of time in sedentary postures in narrow cars; deaths were also noted. Furthermore, although because combined oral contraceptives may cause irregular menstruation and endometriosis, this medication is a well-known risk factor for thrombosis (2).

In April 2016, the Kumamoto Earthquakes (Japan Meteorological Agency) occurred; these included three magnitude 7 earthquakes and their subsequent numerous aftershocks. Kumamoto is located in Southwest Japan; Fig. 1 shows the location of Kumamoto City on the island of Kyushu, Japan.
We herein present the first case of LFT due to the combination of oral contraceptive use and the practice of spending nights in cars when the earthquakes occurred.

\section{Case Report}

A 40-year-old woman visited the Department of Obstetrics and Gynecology in our hospital because of a complaint of sudden dyspnea on effort. She was previously diagnosed with endometriosis and prescribed a combination oral contraceptive pill (drospirenone/ethinylestradiol betadex, trade name; Yaz ${ }^{\mathrm{TM}}$, Bayer, Leverkusen, Germany). Following the Kumamoto Earthquakes and subsequent aftershocks in April 2016, she spent 7 nights in a vehicle. She noticed sudden dyspnea on effort when she walked outside the car on the 8 th morning after the first earthquake. Although she walked around for personal reasons during the daytime, she spent nights in her small car with her legs in a hanging position. She noticed swelling and pain in her left lower extremity,

${ }^{1}$ Department of Cardiovascular Medicine, Graduate School of Medical Sciences, Kumamoto University, Japan and ${ }^{2}$ Department of Obstetrics and Gynecology, Graduate School of Medical Sciences, Kumamoto University, Japan Received for publication May 31, 2016; Accepted for publication June 20, 2016 Correspondence to Dr. Daisuke Sueta, sueta-d@kumamoto-u.ac.jp 

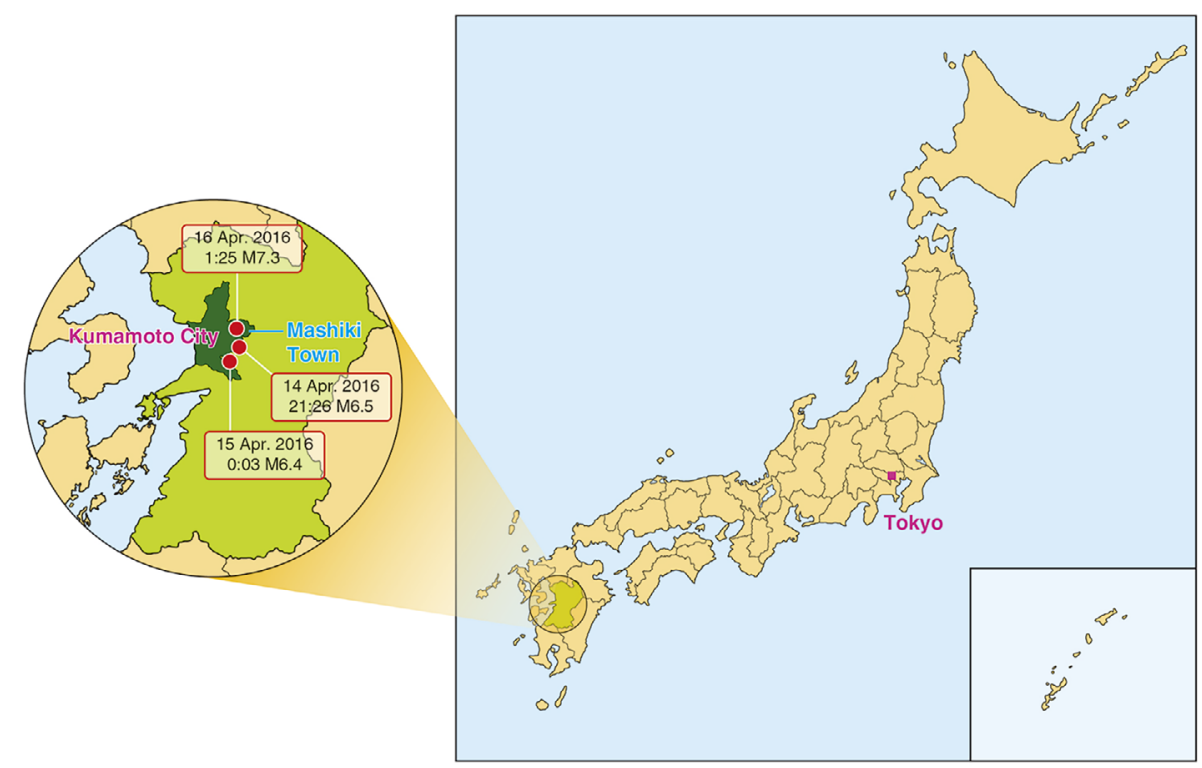

Figure 1. Kumamoto City, Southwest Japan. The location of Kumamoto City in Kyushu, Japan. The epicenter of the Kumamoto Earthquake in 2016 is indicated by the red circles. The date and time indicate local time. M: magnitude

(A)

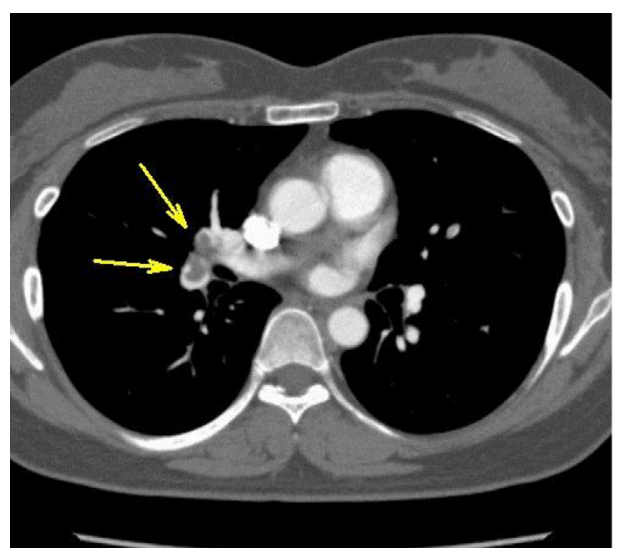

(B)

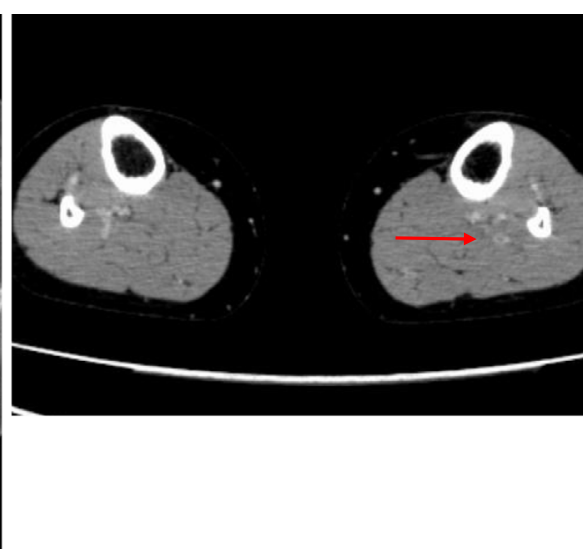

Figure 2. Contrast-enhanced computed tomography on the first visit. (A) A contrast deficit in the bilateral pulmonary artery (the yellow arrow indicates the right pulmonary artery). (B) A contrast deficit in the left lower extremity (red arrow).

and her serum D-dimer levels were $13.2 \mu \mathrm{g} / \mathrm{mL}$. Deep vein thrombosis (DVT) was suspected by her home doctor. A contrast-enhanced computed tomography (CT)-scan revealed a contrast deficit in the bilateral pulmonary artery (Fig. 2A) and in the left lower extremity (posterior tibial, soleus and gastrocnemius vein) (Fig. 2B). Her right ventricular function was intact (estimated pulmonary artery pressure $=29 / 8$ $\mathrm{mmHg}$ in cardiac ultrasound). Her plasma brain natriuretic peptide and high-sense troponin $\mathrm{T}$ concentration levels were $97.2 \mathrm{pg} / \mathrm{mL}$ and $0.0061 \mathrm{ng} / \mathrm{mL}$, respectively. She was diagnosed with PTE and admitted to our department. On admission, her blood pressure was $129 / 80 \mathrm{mmHg}$ and her heart rate was 72 beats per minute. Her degree of oxygen saturation $\left(\mathrm{SaO}_{2}\right)$ in arterial blood gas was $97.7 \%$. Her body mass index was $24.4 \mathrm{~kg} / \mathrm{m}^{2}$. Electrocardiography and cardiac ul- trasound did not indicate heart failure. An investigation of most factors related to thrombus formation (including protein $\mathrm{C}$, protein $\mathrm{S}$, antithrombin, and antiphospholipid antibodies) revealed that all such factors were normal. The discontinuation of the oral contraceptive and the administration of rivaroxaban (30 mg, daily), a direct oral anticoagulant (trade name: Xarelto ${ }^{\mathrm{TM}}$, Bayer) was initiated according to the results of the EINSTEIN-PE trial (3). After 7 days, a follow-up contrast-enhanced CT scan revealed a reduction in the thrombosis (Fig. 3). The patient was followed up with rivaroxaban.

The patient gave her consent for the publication of this study. 


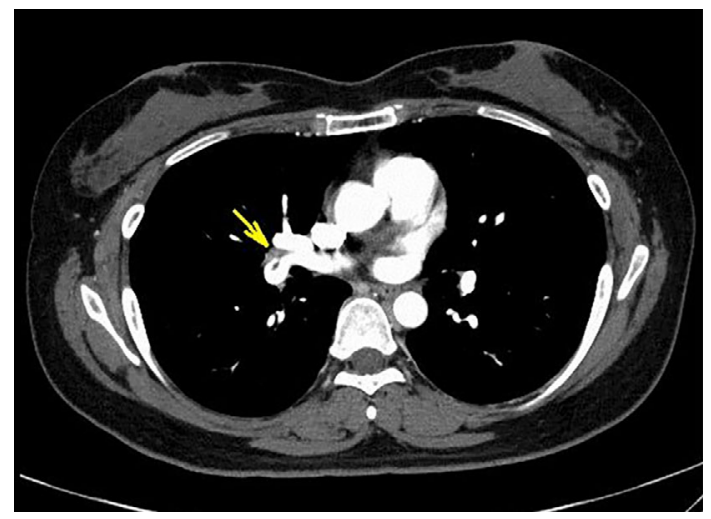

Figure 3. Contrast-enhanced computed tomography at 7 days after the initiation of anticoagulation therapy. The yellow arrow indicates reduced thrombosis.

\section{Discussion}

Pulmonary thrombosis from long-term sedentary practices was reported by a number of residents who were housed in air-raid shelters; these individuals ultimately died of pulmonary embolism (1).

The first recorded case of this pathology due to flying on an airplane was reported in 1954 (4). In 1968, DVT resulting from a long-haul flight crossed a patient's foramen ovale - the patient died of brain thrombosis (5). In 1977, Symington investigated 3 cases in which the developed DVT after flights, and referred to the condition as "economy class syndrome" (6). The incidence of lower extremity DVT and PTE increased after the Mid-Niigata Prefecture Earthquake in 2004. In the Mid-Niigata Prefecture Earthquake in 2004, the Niigataken Chuetsu-oki Earthquake in 2007, and the Great East Japan Earthquake (March, 2011) (7), the DVT-positive rate was higher in the shelters that were located close to the epicenter and the shelters in tsunami-damaged areas. When traveling, there is an association between time spent in the vehicle and the incidence of DVT (8). In females, immobility is a risk factor for DVT. (9) Thus, in females, sleeping in a vehicle after a disaster increases the risk of venous thromboembolism (VTE) over time.

The relationship between combined oral contraceptives and VTE has been reported in several studies (10-13) and subsequent large-scale studies (14-16), including a metaanalysis (2). Thus, combined oral contraceptives are a wellrecognized risk factor for thrombosis. Furthermore, additional risk factors for VTE include obesity, pregnancy, lower extremity operations (17), malignant disease (18), heart failure, and thrombotic diathesis (antithrombin deficiency, protein $\mathrm{C}$ deficiency, protein $\mathrm{S}$ deficiency, plasminogen disorders, high lipoprotein(a) concentration levels, antiphospholipid antibody syndrome, and hyperhomocysteinemia). The mechanisms by which PTE occurred in the present case were thought to involve the induction of thrombus formation by long-term sedentary tendencies and dehydration due to water and food shortages in addition to the patient's oral contraceptive use. Although the patient had been taking oral contraceptives for 6 years, there had not been any evidence to indicate the development of VTEs. Thus, the most critical cause was assumed to be a spending the night in her car, both factors may have contributed the formation of VTEs. Furthermore, in this case, the patient could not sleep for extended periods of time because the car was not comfortable. Sleep shortage might contribute to the development of thrombosis. Importantly, it is essential that all medical staff and evacuees seeking shelter in vehicles be aware of this condition when disasters occur. We should let all evacuees, particularly women who are taking oral contraceptives, know how to avoid VTEs.

To the best of our knowledge, this case represents the first report of a pulmonary thromboembolism in an evacuee who was seeking shelter in a vehicle and taking oral contraceptives.

The authors state that they have no Conflict of Interest (COI).

\section{Acknowledgement}

We thank all of the paramedical staff and clinical secretaries for their kind support during this work.

\section{Devotion statement}

This report is dedicated to all victims of the 2016 Kumamoto Earthquakes.

\section{References}

1. Simpson K. Shelter deaths from pulmonary embolism. Lancet $\mathbf{2 3 6}$ : 744, 1940.

2. Lidegaard $\varnothing$, Nielsen LH, Skovlund CW, Skjeldestad FE, Løkkegaard E. Risk of venous thromboembolism from use of oral contraceptives containing different progestogens and oestrogen doses: Danish cohort study, 2001-9. BMJ 343: d6423, 2011.

3. Büller HR, Prins MH, Lensing AW, Decousus H, Jacobson BF, Minar E, et al. Oral rivaroxaban for the treatment of symptomatic pulmonary embolism. New England Journal of Medicine 366: 1287-1297, 2012.

4. Homans J. Thrombosis of the deep leg veins due to prolonged sitting. New England Journal of Medicine 250: 148-149, 1954.

5. Beighton PH, Richards PR. Cardiovascular disease in air travellers. British Heart Journal 30: 367, 1968.

6. Symington IS, Stack BH. Pulmonary thromboembolism after travel. British Journal of Diseases of the Chest 71: 138-140, 1977.

7. Ueda S, Hanzawa K, Shibata M, Suzuki S. High prevalence of deep vein thrombosis in tsunami-flooded shelters established after the great East-Japan earthquake. The Tohoku Journal of Experimental Medicine 227: 199-202, 2012.

8. Chandra D, Parisini E, Mozaffarian D. Meta-analysis: travel and risk for venous thromboembolism. Annals of Internal Medicine 151: 180-190, 2009.

9. Kabrhel C, Varraso R, Goldhaber SZ, Rimm E, Camargo CA. Physical inactivity and idiopathic pulmonary embolism in women: prospective study. BMJ 343: d3867, 2011.

10. Bloemenkamp KW, Helmerhorst F, Rosendaal F, Vandenbroucke J, Büller H. Enhancement by factor V Leiden mutation of risk of deep-vein thrombosis associated with oral contraceptives containing a third-generation progestagen. The Lancet 346: 1593-1596, 
1995.

11. Jick H, Jick S, Gurewich V, Myers M, Vasilakis C. Risk of idiopathic cardiovascular death and nonfatal venous thromboembolism in women using oral contraceptives with differing progestagen components. International Journal of Gynecology and Obstetrics 1: 82, 1996.

12. Poulter N, Chang C, Farley T, Meirik O, Marmot M. Venous thromboembolic disease and combined oral contraceptives: results of international multicentre case-control study. World Health Organization Collaborative Study of Cardiovascular Disease and Steroid Hormone Contraception. Lancet 346: 1575-1582, 1995.

13. Farley T, Meirik O, Chang C, Marmot M, Poulter N. Effect of different progestagens in low oestrogen oral contraceptives on venous thromboembolic disease. World Health Organization Collaborative Study of Cardiovascular Disease and Steroid Hormone Contraception. Lancet 346: 1582-1588, 1995.

14. van Hylckama Vlieg A, Helmerhorst F, Vandenbroucke J, Doggen C, Rosendaal F. The venous thrombotic risk of oral contraceptives, effects of oestrogen dose and progestogen type: results of the MEGA case-control study. BMJ 339: b2921, 2009.
15. Lidegaard $\varnothing$, Løkkegaard E, Svendsen AL, Agger C. Hormonal contraception and risk of venous thromboembolism: national follow-up study. BMJ 339: b2890, 2009.

16. Dinger J, Assmann A, Möhner S, Do Minh T. Risk of venous thromboembolism and the use of dienogest-and drospirenonecontaining oral contraceptives: results from a German case-control study. Journal of Family Planning and Reproductive Health Care 36: 123-129, 2010.

17. Sueta D, Kaikita K, Okamoto N, Arima Y, Ishii M, Ito M, et al. A novel quantitative assessment of whole blood thrombogenicity in patients treated with a non-vitamin $\mathrm{K}$ oral anticoagulant. International Journal of Cardiology 197: 98-100, 2015.

18. Sueta D, Hokimoto S. Onco-cardiology: Present and future. International Journal of Cardiology 215: 38-40, 2016.

The Internal Medicine is an Open Access article distributed under the Creative Commons Attribution-NonCommercial-NoDerivatives 4.0 International License. To view the details of this license, please visit (https://creativecommons.org/licenses/ by-nc-nd/4.0/).

(C) 2017 The Japanese Society of Internal Medicine http://www.naika.or.jp/imonline/index.html 